\title{
Intracystic Nodule in a Rathke's Cleft Cyst
}

\author{
Sinead Culleton, Hong Kuan Kok, Seamus Looby, Alan O’Hare, John Thornton, Paul Brennan, \\ Hamed Asadi
}

Keywords: magnetic resonance imaging, neuroimaging

doi:10.1017/cjn.2016.283

Can J Neurol Sci. 2016; 43: 850-851

\section{Case Presentation}

An 11-year-old boy presented to the Emergency Department with a two-month history of constant daily frontal headaches which gradually progressed to include visual disturbance. There was no significant prior medical or family history. On examination he was apyrexic and had a bitemporal hemianopia visual field defect. The remainder of his neurological examination was normal. Blood investigations including a full blood count and serum electrolytes were normal with no biochemical evidence of pituitary dysfunction. He underwent an MRI brain for further evaluation (Figure $1 \mathrm{~A}-\mathrm{C}$ ) which confirmed the presence of a large sellar mass lesion with suprasellar extension. Despite the initial clinical diagnosis of a craniopharyngioma, radiological diagnosis of a Rathke's cleft cyst was made with high confidence.

Rathke's cleft cysts are derived from remnants of the embryological Rathke's pouch. They can be sellar, suprasellar or even infrasellar in location. ${ }^{1,2}$ These cysts are usually asymptomatic and are frequently diagnosed as incidental findings on imaging studies. Due to their proximity to many important structures such as the pituitary, hypothalamus and as in this case, the optic chiasm, ${ }^{1,2}$ they may result in compression on these structures. The main differential diagnosis includes a cystic pituitary adenoma and a craniopharyngioma. ${ }^{1}$ Craniopharyngiomas and Rathke's cleft cysts share a similar embryological origin and therefore may be found in similar locations. ${ }^{3}$ Craniopharyngiomas have a bimodal peak, however Rathke's cleft cysts are usually more common in middle aged females. In this age group the adamantinomatous subtype of craniopharyngiomas are the most common, and up to approximately $90 \%$ may calcify. In contrast, Rathke's cleft cysts rarely calcify. There was no evidence of calcification in this case on both CT and MRI (not shown).

It may be difficult to distinguish between a craniopharyngioma and a Rathke's cleft cyst clinically and radiologically. However, an important differentiating feature to identify is an intracystic nodule, which is considered a pathognomonic imaging feature of a Rathke's cleft cyst. This nodule is typically T1 hyperintense and is obscured by the equally $\mathrm{T} 1$ hyperintense cyst contents with no enhancement following gadolinium administration. However, it is hypointense on T2-weighted sequences (Figure 2) making it easily distinguishable from surrounding hyperintense cystic fluid. ${ }^{1}$ Although nodules are an occasional imaging feature of craniopharyngiomas, these are usually enhancing mural nodules

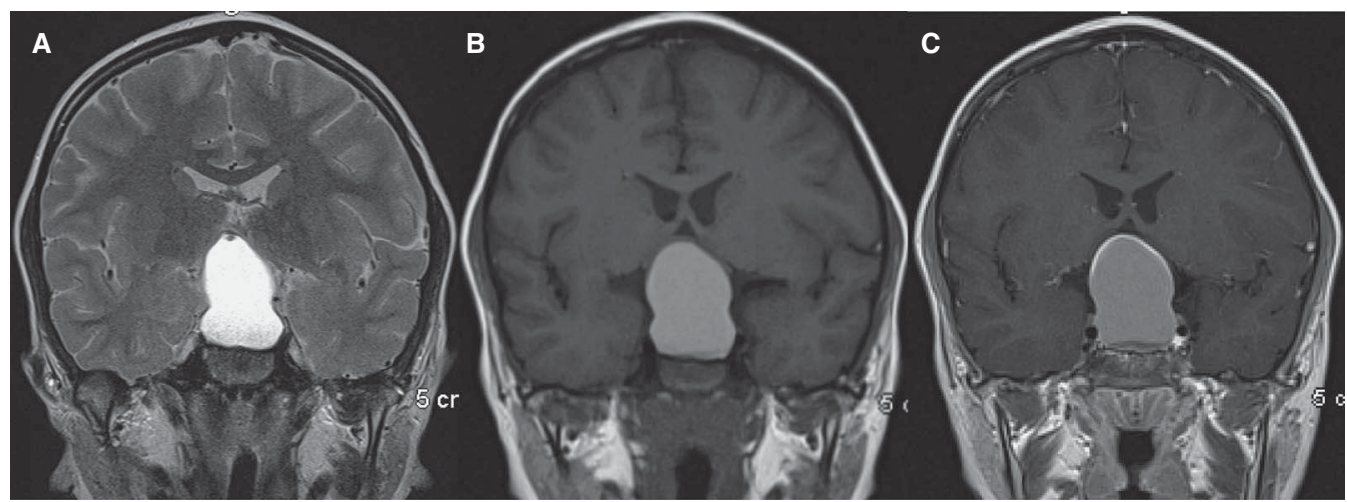

Figure 1: (A) T2-weighted, (B) T1-weighted non-contrast and (C) T1-weighted post-contrast coronal images, demonstrating a large mass in the sella with suprasellar extension, compressing the optic chiasm. There is associated widening and bony remodeling of the sella consistent with a chronic process. The imaging findings are suggestive of either a Rathke's cleft cyst or craniopharyngioma.

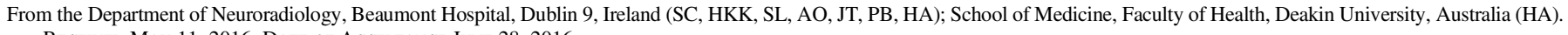
Received May 11, 2016. Date of Acceptance June 28, 2016.

Correspondence to: Hamed Asadi, School of Medicine, Faculty of Health, Deakin University, Pigdons Road, Waurn Ponds, VIC 3216, Australia. Email: asadi.hamed@gmail.com. 


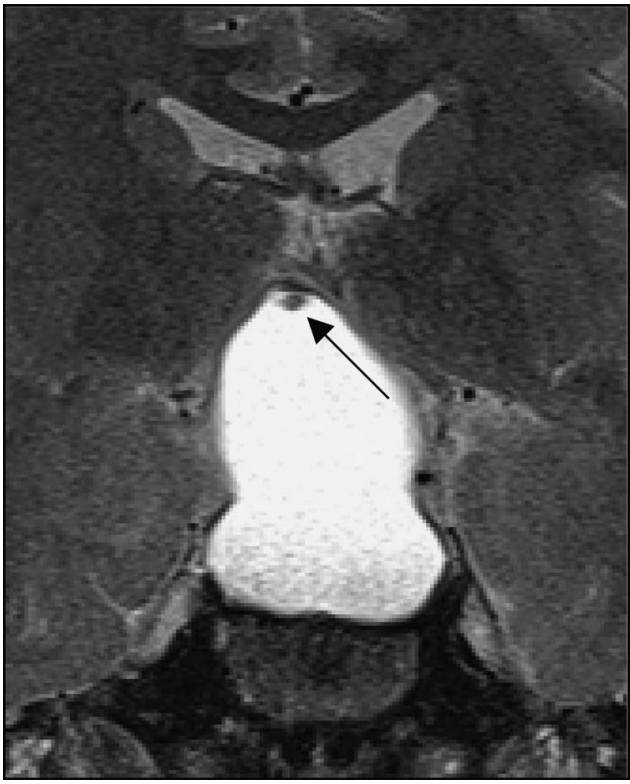

Figure 2: Magnified T2-weighted coronal image with the hypointense nodule highlighted (arrow) characteristic of Rathke's cleft cyst, confirming the pre-operative imaging diagnosis.

and are T2 hyperintense compared to the hypointense Rathke's cleft intracystic nodule. ${ }^{1,4,5}$ This case highlights an important imaging feature that may help to differentiate between two important entities. Successful resection of the lesion confirmed that this was a Rathke's cleft cyst, and the patient's clinical symptoms improved.

\section{Disclosures}

Sinead Culleton, Hong Kuan Kok, Seamus Looby, Alan O'Hare, John Thornton, Paul Brennan, and Hamed Asadi declare no conflict of interest.

\section{REFERENCES}

1. Byun WM, Kim OL, Kim D. MR imaging findings of Rathke's cleft cysts: significance of intracystic nodules. AJNR Am J Neuroradiol. 2000;21:485-8

2. Rao VJ, James RA, Mitra D. Imaging characteristics of common suprasellar lesions with emphasis on MRI findings. Clinical Radiology. 2008(8);63:939-47.

3. Megdiche-Bazarbacha H, Hammouda BK, Aicha AB, et al. Intrasphenoidal Rathke's cleft cyst. AJNR Am J Neuroradiol. 2006;27(5):1098-100.

4. Hald JK, Eldevik OP, Skalpe IO. Craniopharyngioma identification by CT and MR imaging at $1.5 \mathrm{~T}$. Acta Radiologica. 1995;36 (2):142-7.

5. Osborn AS. Miscellaneous tumours, cysts and metastases. Diagnostic Neuroradiology Ed 1. St Louis: Mosby. 1994:626-70. 